\title{
ERRATUM
}

Miodrag Milojkovic $\cdot$ Zlatko Hrgovic $\cdot$ Nicolai Maass

Walter Jonat · Igor Hrgovic · Damir Buković

Sinisa Sijanovic

\section{Assessment of reliability endometrial brush cytology in detection etiology of late postmenopausal bleedings}

Published online: 9 October 2004

(C) Springer-Verlag 2004

\section{Arch Gynecol Obstet (2004) 269:259-262}

The list of authors was incomplete. It should be as following:

Miodrag Milojkovic $\cdot$ Zlatko Hrgovic Nicolai Maass · Walter Jonat · Igor Hrgovic

Damir Buković · Sinisa Sijanovic 